\title{
CAminhos bifurCantes Na EdUCAÇÃo InCLUSIVA: INCLUSÕES E REBELdias SILENCIOSAS NA EDUCAÇÃo PÚBliCA
}

\author{
Ana Lucia C. Heckert $\star$ \\ Ricardo Bodart de Andrade $\star$
}

\begin{abstract}
RESUMO
Este artigo apresenta parte das reflexões efetuadas na pesquisa de mestrado "Políticas inclusivas no chão da escola: usinagens e rebeldias no front-dabatalha" realizada em duas escolas de um município situado na região norte do estado do Espírito Santo. Por meio de conversações buscou-se cartografar os processos de inclusão gestados nas práticas educacionais. Nosso temário geral foi a Educação Inclusiva, campo de intervenção usualmente associado à idéia de inclusão de pessoas com Necessidades Educacionais Especiais (NEE) no ensino regular. Abordamos o tema utilizando especialmente os instrumentos analíticos oferecidos por Michael Hardt e Toni Negri, e Michel Foucault acerca das práticas sociais, dos processos de inclusão e do biopoder. A pesquisa realizada apontou que os modos instituídos que tecem a Educação produzem o chamado fracasso escolar, invisibilizando recusas e inventividades. Apontou ainda, que modos de educar podem revolucionar processos de inclusão diferencial compondo alianças que fortaleçam essas vidas "marginais".
\end{abstract}

Palavras-chave: educação pública; inclusão diferencial; práticas sociais.

\section{Rupturing Paths in inclusive education: inclusions}

\section{AND SILENT REBELLIONS IN THE PUBLIC EDUCATION}

\begin{abstract}
:
This article presents some reflections made on the masters degree research known as "Políticas inclusivas no chão da escola: usinagens e rebeldias no front-da-batalha" (Inclusive policy on the school floor: machining and rebellion at the battlefront). This research took place in two schools from a city at the north region of the state of "Espirito Santo" in Brazil. The inclusion processes

\footnotetext{
^ Professora do departamento de psicologia da UFES e do Programa de Pós-Graduação em Psicologia Institucional/UFES. Endereço: Universidade Federal do Espírito Santo, Departamento de Psicologia. Avenida Fernando Ferrari, 514. Goiabeiras, Vitoria, ES - Brasil. CEP: 29060-900. E-mail: anaheckert@uol.com.br Especialização em Intervenção Sistêmica com Famílias pelo Instituto Crescent/FDV (2005) e Mestrado em Psicologia Institucional pelo Programa de Pós-Graduação em Psicologia Institucional (PPGPSI) - UFES (2009).

E-mail: rba.psicologia@gmail.com
}

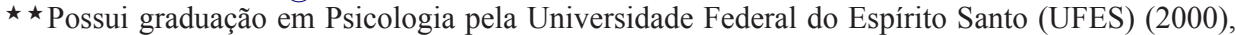


managed by the educational system were mapped through reasoning. The main theme considered in the research was the Inclusive Education. This intervention field is usually associated to people with special educational needs who study at regular schools. The themes were approached following Michael Hardt, Toni Negri and Michel Foucault ideas regarding social practices, inclusion processes and biopower. The research showed that the school failure is produced by the established Educational ways. It also showed that the way people educate can revolutionize the differential inclusion processes, making alliances which strengthen these marginal lives.

Keywords: public education; differential inclusion; social practices.

\section{EddCAÇÃO E INCLUSÃO ESCOLAR COMO PROCESSOS DE INCLUSÃO DIFERENCIAL}

O presente trabalho vem apresentar parte das reflexões de uma pesquisa de mestrado "Políticas inclusivas no chão da escola: usinagens e rebeldias no frontda-batalha" (ANDRADE, 2009) realizada em 02 escolas de um município situado na região norte do estado do Espírito Santo. Por meio de conversações com os sujeitos do cotidiano destes estabelecimentos buscou-se cartografar os processos de inclusão gestados nas práticas educacionais.

Nosso temário geral foi a Educação Inclusiva, campo de intervenção usualmente associado à idéia de inclusão de pessoas com Necessidades Educacionais Especiais (NEE) no ensino regular. Procuramos abordar o tema utilizando especialmente os instrumentos analíticos oferecidos por Hardt e Negri (2005) e Foucault (2005, 2006a, 2006b, 2006c) acerca das práticas e dos processos de inclusão.

Foucault afirma que não há prática sem teoria, nem teoria sem prática, de forma que cada uma compreende aspectos da outra e ambas configuram um posicionamento num jogo de forças. Nesse sentido, tomamos o próprio ato de pesquisar como uma intervenção, uma ação no mundo. Concordamos com Foucault (2006a, p. 71) na afirmação de que "[...] uma 'teoria' é o sistema regional de lutas [...]", isto é, um conjunto de ações que delimitam certos territórios de embate e dispara certos efeitos na Vida, ${ }^{1}$ produzindo-a, reinventando-a.

$\mathrm{Na}$ esteira desse sentido foucaultiano de produção da Vida, Hardt e Negri (2005) distinguem a peculiaridade dos processos inclusivos contemporâneos apontando seus modos de expressão. De acordo com esses autores, o Império como condição planetária atual do Capital se mantém por meio de processos difusos de "inclusões diferenciais", produção pela qual tudo e qualquer um é incluído, diferencialmente encaminhado e gerenciado num grande sistema de controle e poder (HARDT; NEGRI, 2005, p. 218).

Incluindo as diferenças numa "noção universal de direito" o Império distingue tais diferenças amenizando-as numa perspectiva cultural, gerenciando-as e hierarquizando-as numa racionalidade econômica generalizada e de controle. A 
rede imperial atua por modulações, com autodeformações dinâmicas, com soluções incompletas e efetivas porque mutantes de um ponto a outro da trama, numa multiplicidade complexa de variáveis. Como uma grande corporação transnacional que empreende diferentes métodos e graus de exploração/repressão dos diversos grupos étnicos que trabalham para ela, o Império "[...] reconhece as diferenças existentes ou potenciais, festeja-as e administra-as em uma economia geral de comando. O triplo imperativo do Império é incorporar, diferenciar e administrar" (HARDT; NEGRI, 2005, p. 220, grifo nosso).

É nessa perspectiva de um processo de inclusão sempre em curso - efetivado numa contínua produção da Vida por meio de ações teóricas e práticas - que tecemos nossas provocações no campo da Educação e da inclusão escolar, compreendendo "exclusão", "inclusão" e "Educação" como processos dinâmicos, conflituosos e em rede, formas e fluxos de uma inclusiva social inevitável.

Ressaltamos que a perspectiva de inclusão da qual partimos pauta-se nas reflexões de Hardt e Negri (2005) e entende-se por inclusão as diferentes formas sociais de geração, composição e gerenciamento da vida, tanto por meios disciplinares do corpo, como por regulações da população. Nesse sentido, inclusão é também produção de vida, de modos de sentir e viver.

Para trabalhar a inclusiva social em sua dimensão de inclusão escolar recorremos a três eixos conceituais, três patamares de pensamento crítico que nos permitiu pensar os processos escolares nessa rede e vislumbrar o caráter produtivo do social e do desejo no social, sempre inclusivo, diferencialmente inclusivo a depender de quem, como e quando.

Nossa pesquisa-intervenção em Aracruz levou na sacola uma noção de produção social da subjetividade, tendo como "presenças" conceituais constantes: (1) a assunção de que há políticas e práticas em curso voltadas para o controle da população por meio da produção da vida (FOUCAULT, 2005; HARDT; NEGRI, 2005; PELBART, 2003); (2) que ela se processa nas filigranas da constituição própria de nosso corpo individual e de nossas maneiras de pensar, sentir e viver (GUATTARI, F.; ROLNIK, S., 2005), as quais continuamente tensionam estratégias de resistência e invenção constante (HARDT; NEGRI, 2005; PELBART, 2003); e (3) que esse processo produtivo do viver perfaz sempre processos de inclusão social. Neste, a Educação Escolar é um dos dispositivos, sendo que, para nós, não há exclusão absoluta e que, por isso, toda Educação, a rigor, é Inclusiva: toda exclusão aparente se dá em algum tipo de inclusão (HARDT; NEGRI, 2005).

No final do século XVIII, na ampliação da sociedade disciplinar, surge um novo tipo de poder; o biopoder. Essa nova tecnologia vai progressivamente imprimindo, dentre outras, três mudanças importantes: (1) criará um novo corpo, corpo-população, sobre o qual vai agir; (2) passará a atentar para fenômenos de outra natureza, não mais individuais, mas pertinentes apenas ao nível da massa, considerando a população em sua duração; e (3), finalmente, agirá com mecanismos com funções diferentes daquelas dos dispositivos disciplinares - individuais - se tratando, sobretudo, de prever alterações e intervir com regulações globais, com vistas a um equilíbrio (FOUCAULT, 2005, p. 292-294). 
Articulam-se então dois poderes: o disciplinar, que atua no corpo por meios disciplinares, e o biopoder, que atua na população por meios regulamentadores. Duas tecnologias de poder que são geradas em tempos cronológicos diferentes e se sobrepõem, agindo complexamente sobre o corpo-individual, disciplinando-o, e sobre a vida, regulando-a (FOUCAULT, 2005, p. 297).

Biopoder como um regime geral de dominação da vida, biopolítica como uma forma de dominação da vida que pode também significar, no seu avesso, uma resistência ativa, e biopotência como a potência de vida da multidão, para além das figuras históricas que até há pouco tentaram representála (PELBART, 2003, p. 86).

O humano é constituído nesse social dinâmico e entrecruzado de forças de naturezas diversas, uma rede inacabada cuja configuração visível momentânea permitiu a diferenciação de uma forma-subjetividade, que usualmente chamamos "indivíduo", "pessoa", "criatura". Ou seja, somos constituídos por jeitos de lidar com o corpo, com a Lei, com a imagem, com abordagens policialescas de vigilância e punição, com os modos de habitar e as alternativas de convívio e deslocamento no terreno, jeitos e intensidades que nos atravessam desde o nascimento. A matéria-prima do Capital está exatamente nas usinagens de formas de pensar/ sentir/estar na Vida, de formas de afetar e ser afetado. No sopro da economia subjetiva, "[...] na microtessitura da vida subjetiva, nas diferentes maneiras que entendemos nossas existências" (GUATTARI; ROLNIK, 2005, p. 53).

Nessa maquinação de produção, toda e qualquer condição é produzida e composta dinamicamente, nada está fora do lugar, nada está excluído, pois produzido que é nessa megalógica de poder do Império, mas diferencialmente forjado: não há exclusão, mas inclusão diferencial (HARDT; NEGRI, 2005). O artista carismático e famoso da mídia, bem pago e esteticamente alinhado está tão incluso socialmente quanto o menino mirrado, subnutrido, miserável e "incógnito"; estão, no entanto, diferencialmente inclusos. É nesse sentido que não há exclusão, não há falta, mas sim inclusões diferenciais e produção: de homens, mulheres, escolas, sucessos, fracassos...

Foi nessa perspectiva de produção social biopolítica por meio de uma micropolítica humana, histórica e sempre inacabada, que procuramos compor alianças com os movimentos de estudantes, educadores e familiares.

\section{Entrevistas, entremeios, entre euCaliptos em AracruZ (ES)}

Buscamos compreender e problematizar em nossa pesquisa os efeitos das "inclusões" efetuadas pelas práticas escolares na vida de estudantes e educadores de escolas municipais em Aracruz/ES. O termo escolar é pertinente, pois queríamos compreender os processos inclusivos que se dão na escola, com ela, por e/ou em torno dela. 
Concentramos as entrevistas para os educadores em 4 perguntas básicas: (1) O que é essa escola na vida dessas crianças?; (2) O que é essa escola na sua vida?; (3) Você conhece a vida dessas crianças?; e (4) O que é educação inclusiva para você? As conversas transitavam por essas perguntas, ao mesmo tempo em que estávamos atentos aos movimentos que permeavam o cotidiano das escolas, que se atualizavam em gestos, fatos, expressões do corpo, ou seja, aos diversos modos de dizer que não se restringem às falas propriamente ditas.

Nesse sentido, procuramos perceber como os educadores pensavam os sentidos da escola para os estudantes e para eles mesmos. Queríamos compreender o que eles conhecem da vida quotidiana desses jovens e como a noção de Educação Inclusiva surgia nesse contexto, evidenciando contrastes entre os diversos modos de pensar/fazer Educação. Trazer essas impressões para composições com as dos jovens, nos possibilitou análises de como a escolarização encaminha essas vidas. Permitiu também perceber consonâncias e dissidências entre as noções de Educação Inclusiva dos profissionais, as dos conhecidos discursos neste campo e as inclusões diferenciais quotidianas, "concretas".

Esse modo de pesquisar compõe o que podemos chamar de um exercício e aprendizado cartográficos. A produção de diferença e a busca de discursos minoritários, confabulados com os intercessores, ${ }^{2}$ são importantes princípios para o nosso exercício cartográfico. O princípio primeiro, por assim dizer, foi o de conceber que a ética, enquanto exercício, "[...] implica, sobretudo, não falar e decidir pelo outro" (HECKERT, 2008, p. 213).

A aposta e o movimento cartográfico se referem às estratégias de formação do desejo no campo social. O desejo produz o campo social, fabrica encontros. Cartografar é um transitar entre direções, direcionamentos expostos aos agenciamentos da trajetória, e não entre objetos e objetivos preestabelecidos. Procurando dar voz e corpo aos afetos que pedem passagem, assume-se parte da investigação com um tipo de sensibilidade possível de prevalecer em seu trabalho (ROLNIK, 1989 apud BOCCO, 2006, p. 52). Se, por um lado, não há um objeto-objetivo a priori, a cartografia comporta uma direção. Implica em fazer escolhas a cada momento de acordo com os agenciamentos que se operam. Essas escolhas fazem diferença.

A noção de cartografia (KASTRUP, 2007) implica em construção e, para nós, ela é tecida na relação, na trama. O exercício para nós foi captar os movimentos que se insinuavam no cotidiano da escola e da vida dos moradores, buscando perceber suas nuances, suas ondulações e inserir-se em algumas delas. $\mathrm{O}$ aprendizado cartográfico pede que o pesquisador se deixe tocar, que permita sustentar a vontade de ir em outra direção da prevista no itinerário, exige continuar sem certezas por muitos momentos, ouvir estranhezas. Nesse sentido, foi imprescindível ouvir as crianças, já que perceber o que se passava com elas, a partir de suas falas e expressividades, era romper com uma tendência de se falar por elas e sobre elas, afirmando e desafirmando o que elas pensam, precisam e querem. 
O desafio foi estabelecer uma escuta do que se passava, conversando com esse movimento. A composição geral que se pretendeu com as entrevistas foi entrelaçar produções dos educadores e estudantes, compreendendo encaminhamentos de vidas pela escolarização, percebendo os movimentos de inclusões diferenciais construídas nos encontros e desencontros da escolarização nesse contemporâneo.

O intuito era o de compor um entrelaçamento entre os apontamentos feitos pelos educadores e as considerações de crianças e jovens. Transitamos pelas significações que a escola e a Educação tomam para esses atores em seus territórios existenciais e suas construções de passado, presente, futuro. Como os educadores pensavam os sentidos da escola para os estudantes e para eles mesmos? O que eles conhecem da vida quotidiana desses jovens? Como a noção de Educação Inclusiva surgia nesse contexto? Queríamos evidenciar os contrastes entre os diversos modos de pensar/fazer Educação. Trazer essas impressões nos possibilitou análises de como a escolarização encaminha essas vidas.

Aracruz é um município ao norte do Espírito Santo, cuja sede central fica a $83 \mathrm{Km}$ da Capital Vitória. O município é conhecido internacionalmente em virtude da Aracruz Celulose S/A, empresa que é referência mundial em produção de pasta branqueada de celulose de eucalipto. "A" história aracruzense nasce numa região hoje chamada de "Santa Cruz" ou "Vila de Santa Cruz", conhecido balneário ao Norte do Espírito Santo com antiga tradição gastronômica. Próxima de território que é foco de nossa pesquisa, essas paragens eram habitadas por índios guaranis e tupiniquins, tendo sido "agraciadas", em 1556, com um núcleo de catequese. Em 16 de dezembro de 1837, são batizadas como Distrito de Santa Cruz, tornado-se município em 3 de abril de 1848 e sendo instalado em 16 de janeiro de 1849. A Vila de Santa Cruz então se torna oficialmente a sede do município Santa Cruz.

Dados de 2007 (PREFEITURA MUNICIPAL DE ARACRUZ, 2008) apontam que o município de Aracruz conta com pouco mais de $3 \%$ do território capixaba e 73.358 residentes. Em 2008 se cogitava em torno de setenta e cinco mil. Apesar do PIB de mais de 32 mil reais por pessoa, seu Índice de Desenvolvimento Humano total e desagregado (IDH) sempre esteve pareado com o índice Nacional. De 1991 a 2000 o IDH aracruzence esteve um pouco acima do índice nacional apenas na Educação, $5^{\circ}$ lugar entre os municípios capixabas (PREFEITURA MUNICIPAL DE ARACRUZ, 2008). Em 2007, Aracruz contava com 54 escolas no município, entre unidades de ensino infantil, fundamental, médio e unidades mistas, algumas com Ensino de Jovens e Adultos (EJA). Atendia a cerca de 14.000 estudantes, entre crianças, jovens e adultos (PREFEITURA MUNICIPAL DE ARACRUZ, 2007).

Relatos informais e entrevistas permitiram perceber as singularidades do município de Aracruz. Os entremeios de uma história que conta o "sobrepeso" de grandes empresas, tomadas de terras indígenas e quilombolas, dependência econômica da prefeitura para com os repasses da Aracruz Celulose S/A (ARCEL). Podemos dizer que a história recente do Município se confunde com a história da Empresa. Segundo Gurgel e Borgneth (2007, p. 77), as atividades da Aracruz Florestal S/A, que plantou as primeiras mudas, se iniciam no municí- 
pio em 1967. Foi recebida como a "salvadora da pátria", chegando ao município em tempos difíceis, quando $54 \%$ dos cafezais tinham sido erradicados. Era o período da industrialização, do "milagre brasileiro" e dos incentivos do Plano Nacional de Desenvolvimento (PND).

O Município de Aracruz tem hoje sua cobertura original de Floresta Atlântica de planície e encosta (Hiléia Baiana) quase totalmente substituída por pastagens e especialmente pelas culturas e reflorestamentos homogêneos com eucalipto. A ARCEL S/A, volta e meia anunciando recordes de produtividade e lucro, chega a registrar em 2005 uma base florestal com 245 mil hectares em 4 estados brasileiros, com 132 mil hectares anunciadas como reservas de matas nativas. Seu território próprio alcançava na época em torno de 405 mil hectares (FUNDAÇÃO GETÚLIO VARGAS, 2007). Em 2007, seu site oficial, hoje (2010) 'fora do ar', referia 280 mil hectares de base florestal em cinco estados brasileiros e cerca de 157 mil hectares de áreas de preservação. Podíamos contar nesse ano, somando um mais um, 437 mil hectares sobre a "jurisdição" da megamáquina de papel (ARACRUZ CELULOSE, 2007)3.

Essa presença da ARCEL dificultava o aparecimento de contrastes e discursos colonizadores "pipocam" por todo município. Como falar em "autonomia" nesse panorama? Estamos diante de um Golias? Onde/como estão os "Davis"? Depoimentos afirmam que a economia do município depende sim do pólo industrial, e depende muito.

A problemática da terra gerada pela ARCEL / FIBRIA vai de encontro aos interesses de índios, quilombolas e ambientalistas desta e de outras regiões. Relatos informais contam histórias conflituosas e até sangrentas ${ }^{4}$, comumente veiculadas na mídia sob a perspectiva do "homem branco", marcando o caráter exploratório e truculento do Capital para com os recursos e comunidades locais. Outrossim, as cercanias do seu sistema portuário (Portocel) contam com condições degradantes de vida, com prostituição, abuso infantil, fome e outras violências. Ao pesquisador interessado, basta caminhar e conversar pelos recantos do município e ouvir, especialmente os de mais idade. A produção midiática desta empresa sobre sua monocultura, seu uso das águas e outros "detalhes" obviamente contrasta com tais relatos.

Capilarmente instalada no município a "fabriqueta" de papel goza de credibilidade local, estadual, nacional e internacional. A Aracruz Celulose é conhecida como uma empresa que respeita o meio-ambiente e se preocupa com a questão social, sendo valorizada por fomentar diversos projetos empresariais, sociais e ambientais e abençoada aparentemente por tudo e todos (GURGEL; BORGNETH, 2007). A caracterização do peso da "megamáquina de papel branco" na economia de Aracruz (em Aracruz, em sua macropolítica, na flora e na fauna, na biopolítica das relações sociais, na micropolítica da subjetividade), pretende compor um panorama do município sem a ingenuidade do frontispício de boa empresa. Evidencia também sua capilaridade nos modos de pensar a vida (a Escola, o público, as relações). 
No que tange à constituição de políticas públicas, relatos apontam que a gestão municipal de 2004 configurou um rompimento de uma alternância bipolar. Depoimentos pelas ruas afirmam ser esta administração uma nova perspectiva em termos de políticas públicas. O termo "público", de uma política pública, em termos de um conjunto de esforços em torno do que é bem comum e uso coletivo (unidades de saúde, escola pública, conselhos comunitários, etc) parece ser uma noção recente neste município.

Entre eucaliptos, lutas, apaziguamentos e redes imperiais são constituídas as políticas de inclusão. Na pesquisa realizada ressaltou-se, para nós, a produção do fracasso escolar como expressão das inclusões diferenciais operadas na atualidade.

\section{A PRODUÇão do FRACASSO ESCOLAR E AS RECUSAS}

Elegemos a produção do fracasso escolar e os diferentes processos de recusa para assentar nossa afirmativa de que há apenas inclusões "diferencialmente" engendradas aqui e ali na rede social. Tal afirmativa "localiza" também, e esse é um dos "pulos do gato", o que entendemos e propomos de combate em favor da vida.

O modo como compreendemos a fabricação dos processos educacionais nos distancia das noções individualizadas de "problemas de aprendizagem", "deficiências" e "soluções pedagógicas" para "o" problema da "exclusão escolar". Percebemos tais questões como produção histórica e social, não passíveis de resolução apenas por mudanças técnicas de conteúdo ou de atitudes em sala de aula. Esta compreensão forçou-nos a confabular com os usuários das escolas percebendo os contrastes entre conteúdos escolares e comunidade local, ideais inclusivos e condições de trabalho do educador. Bem como nos fez lembrar que a vida pulsa em meio às produções da escola e da escolarização na sociedade contemporânea, produções essas em que a perspectiva inclusiva toma espaço.

Uma das linhas que tecem o chamado fracasso escolar, e que para nós se constitui num fator importante de análise, é a vinculação temporária de trabalho de muitos profissionais da educação (ou professores). A precarização dos contratos de trabalho gera descontinuidades que incidem na saúde do trabalhador e nas vinculações possíveis que se criam (e não se criam) com os alunos e as questões da região. Heckert (2000) nos lembra dos múltiplos entrelaçamentos que configuram os processos educacionais, atentando para a "diluição" da escola nos processos de regulação do mercado. Dentre tais processos de regulação, a precarização do trabalho do educador emerge como analisador ${ }^{5}$ do lugar da escola nessa produção social biopolítica.

Como criar vínculos mudando de escola várias vezes? E as possibilidades de um trabalho que construa alguma permanência e promova intervenções nãoindividualizantes que facultem transformações sociais na região? Consideramos que essas transformações demandam tempo, continuidade, debate, errância. Com essas vinculações temporárias no conjunto da educação institucionalizada o discurso da carência (dos alunos, de suas famílias, do bairro...) se perpetua. 
Outrossim, a produção do fracasso escolar, sentido como tal numa estrutura oficial de Escolarização, nos lembra das tramas capital-escola. Longe de ser uma conceituação distante as forças de Capital estão nas tramas de currículos, nas pedagogias e psicologias idealizadas e se misturam no quotidiano do educado. Expectativas messiânicas depositadas na escola e valores afins ao capital são reativados em conteúdos distantes das experiências de escassez e modos de vida de crianças pobres, produzindo uma docência da insistência, uma docência do resgate:

[...] porque a gente acha assim... que, dá pra fazer, mas não tem condições de fazer [...] estou numa fase assim meio, decepcionada $[. .$.$] Tem caso de alunos aqui que já está com$ 50 faltas, que a gente não consegue resgatar, não consegue trazer para a escola (Profissional entrevistado).

Não se trata de haver uma teoria da pedagogia lá (na academia) que ao ser aplicada aqui (na comunidade tal) dê errado. Há produções teóricas que fazem parecer que os confrontos que se dão no chão-de-escola se devem a uma questão de teoria mal aplicada, talvez uma pedagogia insuficiente, que fracassa em não-resgatar. Entendemos que há a produção de um sentimento de incompetência e incapacidade dentro da escola. Uma tendência de constatar que a escola não "salva" essas crianças, mas deveria fazê-lo e que os professores são os "culpados" por esse não fazer.

Nessa idealização da Escola a educação é a medida da doutrinação. Algumas vezes os alunos "apenas" afirmam outras coisas, elaboradamente e educadamente. Geralmente, entretanto, "deseducadamente" debocham, rejeitam, atacam, vão embora. A escuta cuidadosa é fundamental tanto numa situação como noutra. Muitos alunos vão à escola, gostam de lá, mas não gostam de estudar; utilizam aquele espaço, público, como lhes agrada. É sutil perceber nisso tudo uma batalha continuada, perceber uma produção de modos de viver, de resistir e não falta de educação, de interesse. Perceber aí embates entre movimentos de cooptação e de recusa, ambos misturados nas relações escolares. São sutis as fronteiras entre uma educação-respeito e uma educação-doutrinação.

Nossa pesquisa-cartografia evidenciou casos de alunos que simplesmente foram embora e abriram mão da merenda, da amizade, do convívio, abriram mão da escola que gostam, pois não gostam de toda a escola, de tudo que ela oferece. Eles não foram expulsos (diretamente), mas ficou desconfortável ficar. Nesse processo, a escola torna-se também saudade, desejo de retorno para um espaçotempo-convívio (possível apenas para o próximo ano, caso consigam retornar à escola). Ficaram na lembrança dos alunos tanto as dores como as pessoas em quem encontraram acolhida.

As situações de sala de aula não se resumem nem àquele espaço-tempo, nem a alguma teima específica. Suas produções e efeitos se estendem! Ressoam na matéria e densidade corporais, na intensidade do pensamento, na ida pra casa, 
na família. Transitam no tempo, no estar do presente, um presente que se mistura com o desejo de futuro, com os sonhos que se tem, aproximando-os, distanciando-os, potencializando e despotencializando a força do vivo.

Nas conversas com as crianças perspectivas de futuro e sonhos chamaram nossa atenção, pois apontavam as dimensões de possibilidades e impossibilidades sentidas por esses jovens, dimensões compostas também nos encontros de seus pulsos de vida com a escolarização. Os estudantes têm coisas a dizer, sentem esses processos, mesmo que não sejam explícitos quanto a isso, pois são afetações muitas vezes silenciadas. Um silêncio "excluído" da escola, incluso diferencialmente para as raias da família, dos amigos mais íntimos.

É incluso diferencialmente também em discursos habituais que desqualificam o aluno ou sua família. Vem-nos à memória a situação de uma mãe que não sabia ao certo porque um aluno não voltara para a escola, um quebra-cabeça que foi se montando aos poucos. $\mathrm{O}$ aluno $\mathrm{A}$, depois de uma fala mais ríspida de um Educador, ficou "sem jeito" de voltar para a escola, não partilhou com a mãe o que houve e simplesmente não voltou mais! Essa autonomia (de não voltar e não dizer) construída com essa mãe que o acolheu acaba também por alimentar o discurso habitual voltado para essa população: aluno desinteressado, que não dá para o estudo, com família desestruturada... Um discurso costumeiro de uma estatística costumeira de um modo costumeiro de avaliar a escola: evasão escolar; diz-se o aluno evadiu, como se essa trama não fosse coletiva.

Em nossas análises sobre o desempenho escolar nas escolas públicas tendemos a excluir as condições político/sociais que produzem as condições de repetência, baixo rendimento e evasão escolar. Não no sentido de dizer que elas explicariam os rendimentos escolares ruins dos pobres, como se, se eles morassem melhor, tivessem uma família "estruturada", comessem bem e tivessem mais estímulos - como as ditas tecnologias modernas -, poderiam render mais. A ressalva é mais grave! É preciso mudar a pergunta: “[...] não mais quem repete [abandona] ou porque repete [desiste], mas "o que se repete" [ou o que é abandonado e o que é produzido]” (BENEVIDES, 1997 apud HECKERT, 2004, p. 152)?

É claro que morar com conforto, comer o suficiente e ter acesso a ferramentas tecnológicas, pode ser bom para uma comunidade, inclusive para o desempenho escolar. Mas a falta disso não é o problema, ou melhor, essa correlação é um 'falso problema' (DELEUZE, 1999). Pode ser bom, pois a depender do engendramento que leva "casa, comida e tecnologia lavada" a comunidades de baixa renda, podemos estar nas raias da caridade apaziguadora e compensatória, muitas vezes oferecidas por grandes empresas em troca de afrouxamentos no cumprimento de leis ambientais e de obrigações tributárias e sociais, as quais, se honradas, dispensariam tais atos de "bondade" empresarial, aparentemente bem intencionados.

A casa ruim, a alimentação de poucas vitaminas e calorias, o convívio familiar dos alunos (pobre de estímulos) e até mesmo fatores biológicos ou intraescolares (como o pouco acesso à tecnologia) não causam o baixo desempenho escolar, mas a complexidade das práticas que constituem essas condições (HE- 
CKERT, 2004: p. 150). Nessa complexidade, vislumbramos a proposição e efetivação forçadas de uma Educação que não atende, ou atende muito pouco, a essa população. O problema para nós é o seguinte: o próprio formato (conteúdo, tempo, ênfases) da escola oferecida à população de baixa renda não teria se construído assim, do jeito que se apresenta, para repetir, nos encontros com "Joãos", "Marias", "Ticos" e "Pixotes", uma mesma maquinação de inclusão diferencial precária dessas vidas, ano após ano, década após década, geração após geração? Isso ninguém contou à Mãe do menino que não voltou mais à escola...

$\mathrm{O}$ que se repete não é a exclusão, mas sim uma inclusiva funcional do sistema capitalista, inerente também à Escola, que mantém a precarização das condições de vida de uma população e os privilégios de poucos. A maquinaria da escolarização parece ficar mais visível se contrastada com essa lógica "econômica" das inclusões diferenciais: acesso universal com a égide da "Escola para Todos" (momento inclusivo); perspectiva inclusiva flexível de acolhimento da diversidade do alunado (momento diferencial) e garantia de aproveitamento de acordo com as aptidões e habilidades (ou limitações e deficiências) individuais (momento gerencial). Esse é um dos efeitos da Educação ou um dos usos possíveis para os tempos, espaços e recursos das escolas.

A sutileza da inclusão escolar diferencial pode ser compreendida, inicialmente, se vislumbramos processos muito comuns na escolarização pública: os moldes educacionais tendem a combinar com valores instituídos de família, de trabalho e ascensão social, os quais não condizem com o quotidiano da maioria da população pobre desse país.

Pensando na Escola como possibilidade de contrapoder na rede do Império, propomos pensar cada educador como um interventor no domínio biopolítico, em que os desejos e movimentos de invenção da comunidade local fossem fomentados por sua prática, em especial em sala de aula. Nessa dimensão - da biopolítica - evidenciamos como importante o trabalho de configurar diferentes maneiras de entender os quotidianos individuais e coletivos, fazer da prática educativa uma reafirmação de modos de viver singulares, mesmo que incomuns, patologizados pelas ciências e fora de forma, de moda, de sucesso. Esses processos inovadores já se dão nas ações quotidianas. Lembramos da intervenção de um dos educadores que relacionava sua temática com as situações de precariedades sociais locais e das formas possíveis de mobilização coletiva. Outro educador questionava o pequeno tempo de recreio, defendendo que ele deveria ser aumentado, já que os alunos não tinham muito tempo para conversar, pois vinham de lugares diferentes da região e não se viam fora da escola.

Essa perspectiva enviesada que procuramos produzir na cartografia com processos inclusivos escolares em Aracruz enxerga o trabalho dessa grande maquinação social de que todos fazemos parte. Enxerga, por isso também, essa vitalidade humana, de inventividade a toda hora, agora, agora, agora! Nesta também tomamos parte! 


\section{INCONCLUSÕES: INCLUSIVA ESCOLAR E COMBATE}

A vitalidade da Escola, assim como as controversas forças de mudanças na Saúde - conquistas do SUS, travessias da luta antimanicomial, reforma psiquiátrica, atenção psicossocial, desinstituicionalização - precisa de profissionais "implicantes" (RODRIGUES, 2009). Profissionais que exijam de si e dos demais, "[...] a cada ensinamento ou recomendação, a análise da participação de tal ensinamento ou recomendação na produção daquilo que aparentemente apenas se constata como 'problema da vida'" (RODRIGUES, 2009: p. 206). Ousamos dizer que a Educação precisa também ser desinstitucionalizada! Primeiramente, no sentido de compreender que o cotidiano educa mais do que os conteúdos, suplantados inclusive pelo próprio modo de fazer escola, que gera a pertinência de se ensinar uns conteúdos e não outros. Em segundo lugar, desinstitucionalizada na possibilidade de negar boa parte daquilo que habitualmente entendemos por educar, uma recusa talvez inevitável para que revoluções em favor do povo de fato se dêem. Revoluções para as quais as formações institucionalizadas (de pedagogos, psicólogos, assistentes sociais...) jamais serão um alimento.

Os modos instituídos na escola - regime de verdade para Foucault (2006a) - são similares aos das academias, das ciências positivistas, dos ideais midiáticos e de consumo e das exigências industriais de exploração do trabalhador. Essa similaridade ajuda a explicar porque os índices de rendimento de estudantes moradores de bairros com rendas médias, média-alta e alta tendem a ser considerados melhores que os rendimentos de estudantes de baixa renda. É que os valores e racionalidades das famílias mais abastadas são similares às tramas que geram os currículos, as avaliações e metas escolares, sendo similares, ao mesmo tempo, aos modos preconizados pelo mundo do trabalho capitalizado.

Martins (2008) propõe um método que tome como referência na análise dos processos sociais aquilo que é limiar, marginal e anômalo. Para nós esse método pode estar presente também na maneira de pesquisar, esta uma forma de intervenção na vida. A lembrança de uma mistura fluida constante de uma biopolítica aracruzence (santacruzence, capixaba, brasileira...) e de uma micropolítica cotidiana (local), esteve conosco nos encontros por essas terras.

Escolhemos para a elaboração deste trabalho algumas das tecelagens que inventamos junto com educadores, estudantes, familiares e moradores, acreditando que "produzir com" é fortalecer essas vi(d)as (pensamentos, sentimentos, práticas...) que tendem para a invisibilidade frente aos modos hegemônicos de viver. Afirmamos essas modulações de alianças marginais como combates estratégicos na rede de inclusão diferencial do Capital, ações indispensáveis por serem intervenções que compõem com os modos de viver dos atores locais. 


\section{Notas}

${ }^{1}$ Vida aqui é entendida para aquém e além de seu aspecto biológico, considerando sua amplitude social, de pensamentos, de afetações, de vínculos, de inventividade e construção de soluções e problemas quotidianos. Vida "[...] inclui a sinergia coletiva, a cooperação social e subjetiva no contexto de produção material e imaterial contemporânea, o intelecto geral. Vida significa inteligência, afeto, cooperação, desejo [...]" (PELBART, 2003, p. 83).

${ }^{2}$ A noção de intercessores que utilizamos aqui vem de Deleuze (2000). Intercessor são pessoas, conceitos, coisas, como as quais construímos um falseamento para exprimir o que precisamos dizer. A idéia de falseamento se coloca por não haver a intenção de representar o que o outro diz, de re-apresentar sua verdade, mas, sim, de sermos tocados pelo outro, que nos compromete numa relação inventada. No desenvolvimento de um pensamento, de um trabalho, criamos intercessores, construídos no entre, no encontro.

${ }^{3}$ A ARCEL, hoje (2010) FIBRIA, refere em site oficial (www.fibria.com.br) uma base de área florestal superior a 1 milhão de hectares. Destes, 393 mil seriam dedicados ao que eles chamam de 'conservação de ecossistemas nativos'. A empresa refere ainda que sua área florestal está presente em 6 estados: Espírito Santo, Bahia, Minas Gerais, Rio Grande do Sul, São Paulo e Mato Grosso do Sul (FIBRIA, 2010). O surgimento da FIBRIA aparece no site da ARCEL, como uma união entre esta empresa e a Votorantim Celulose e Papel (VCP), referidas como duas empresas brasileiras com forte presença no mercado global de produtos florestais (ARCEL, 2010). Já no domínio virtual da FIBRIA, a mesma é anunciada como uma "líder em celulose de mercado" que nasce da incorporação da antiga ARCEL - ali nomeada de 'Aracruz' - pela VCP, anunciando seus 15 mil empregados e sua capacidade de produção em torno de 5,4 milhões de toneladas de celulose e 300 mil toneladas de papel por ano (FIBRIA, 2010). A distinção entre 'união' e 'incorporação' nesse caso - somada à estranha escrita que anuncia a incorporação pela VCP da 'Aracruz' e não da 'ARCEL' ou 'Aracruz Celulose' - seria mero eufemismo para a violação ambiental oficializada?

${ }^{4}$ Informações atuais sobre conflitos com a ARCEL podem ser acessados nas páginas do "Brigada Indígena", grupo de apoio às comunidades Tupiniquim e Guarani nos municípios de Aracruz (http://www.autistici.org/brigada/) e da FASE (www.fase.org.br).

${ }^{5}$ Os analisadores são acontecimentos, que põem em evidência, em movimento e em análise, determinadas relações de força, determinadas situações, enfim, um conjunto de relações, que até esse momento não estavam em visibilidade, não estavam em questão ou não eram discutidas da maneira que, a partir de então, passa a se colocar (LOURAU, 2004, p. 131-132).

${ }^{6}$ Menção à conhecida proposta popular, e comumente jocosa, que oferece "casa, comida e roupa lavada" a um (a) possível pretendente, com óbvios interesses de convívio continuado sob determinadas condições de compromisso, casamento ou algo do gênero. Uma proposta nesses termos pode ser boa, mas não será necessariamente assim para todas as partes envolvidas.

\section{REFERÊNCIAS}

ANDRADE, R. B. Políticas inclusivas no chão da escola: usinagens e rebeldias no front da batalha. 2009. Dissertação (Mestrado em Psicologia Institucional) Universidade Federal do Espírito Santo, Fundação de Apoio à Pesquisa, Espírito Santo, 2009. Orientador: Ana Lúcia Coelho Heckert.

ARCEL. Fibria, nasce uma nova empresa. Disponível em: <www.aracruz.com. br/show_press.do?act=news\&id=1000873\&lang=1>. Acesso em: 24 out. 2010.

BOCCO, F. Cartografias da infração juvenil. 2006. 181 f. Dissertação (Mestrado em Psicologia)-Instituto de Ciências Humanas e Filosofia - Universidade Federal Fluminense, Niterói, 2006.

DELEUZE, G. Conversações. 3. ed. reimp. Rio de Janeiro: 34, 2000. Coleção TRANS. 
DELEUZE, G. Bergsonismo. Tradução de Luiz B. L. Orlandi. São Paulo: 34, 1999. p. 7-26.

FIBRIA. Onde estamos. Disponível em: <http://www.fibria.com.br/web/pt/ institucional/onde.htm.> Acesso em: 25 out. 2010.

FOUCAULT, M. Aula de 17 de Março de 1976. In: . Em defesa da sociedade: curso no Collège de France (1975-1976). São Paulo: Martins Fontes, 2005. p. 285-315.

FOUCAULT, M. Microfisica do poder. Rio de Janeiro: Graal, 2006a.

FOUCAULT, M. Poder e Saber. In: MOTTA, M. (Org.). Estratégia, Saber-Poder. Porto Alegre: Forense Universitária: 2006b. v. IV, p. 223-240. Coleção Ditos \& Escritos.

FOUCAULT, M. Vigiar e punir: nascimento da prisão. Petrópolis: Vozes, 2006c.

FUNDAÇÃO GETÚLIO VARGAS. Das árvores aos lares: a geração de renda, emprego, divisas e impostos da Aracruz celulose. Disponível em: $<\mathrm{http} / / \mathrm{www}$. aracruz.com.br/pdf/arquivofgv.pdf>. Acesso em: 2 Dez. 2007.

GUATTARI, F.; ROLNIK, S. Micropolítica: cartografias do desejo. Petrópolis: Vozes, 2005.

GURGEL, A. P.; BORGNETH F. Primo Bitti: a construção de Aracruz. Vitória: Aracruz Celulose, 2007.

HARDT, M.; NEGRI, A. Império. Rio de Janeiro: Record, 2005.

HECKERT, A. L. C. Ética e técnica: exercício e fabricações. In: PINHEIRO, R.; MATTOS, R. (Org.). Cuidar do cuidado: responsabilidade com a integralidade das ações de saúde. Rio de Janeiro: CEPESC/ABRASCO/IMS, 2008. v. 1, p. 213-230.

HECKERT, A. L. Narrativas de resistências: educação e políticas. 2004. 311 f. Tese (Doutorado em Educação)-Universidade Federal Fluminense, Niterói, 2004.

HECKERT, A. L. Os Desafios da educação na contemporaneidade. In: SILVA, A. A.; BARROS M. E. B. (Org.). Psicopedagogia: alguns hibridismos possíveis. Vitória: Saberes Instituto de Ensino, 2000. p. 11-18. 
KASTRUP, V. Cartografia e Pesquisa. Palestra ministrada no Programa de PósGradução em Educação da Universidade Federal do Espírito Santo (UFES). Vitória: Universidade Federal do Espírito Santo, 02 jun. 2007.

LOURAU, R. Uma apresentação da análise institucional. In: ALTOÉ, S. (Org.). René Lourau: Analista Institucional em Tempo Integral. São Paulo: Hucitec, 2004. p. 128-139.

MARTINS, J. S. A sociabilidade do homem simples. São Paulo: Contexto, 2008. $172 \mathrm{p}$.

PELBART, P. P. Vida capital: ensaios de biopolítica. São Paulo: Iluminuras, 2003.

PREFEITURA MUNICIPAL DE ARACRUZ. A Cidade. Disponível em: <http:// www.pma.es.gov.br/cidade/>. Acesso em: 27 out. 2008.

PREFEITURA MUNICIPAL DE ARACRUZ. Dados e informações sobre o atendimento escolar pela rede municipal de ensino. Documento eletrônico oficial no formato Excel recebido eletronicamente. [mensagem pessoal]. Mensagem recebida por <rba.psicologia@gmail.com>em 13 set. 2008.

RODRIGUES, H. B. C. Formação 'psi': reforma psiquiátrica, atenção psicossocial, desinstitucionalização. In: MOURÃO, J. C. (Org.). Clínica e política 2: subjetividade, direitos humanos e invenção de práticas clínicas. Rio de Janeiro: GTNM/Abaquar, 2009. p. 201-206.

Recebido em: novembro de 2009 Aceito em: setembro de 2010 
